\title{
ISLAMIC FINANCIAL DEVELOPMENT, ECONOMIC GROWTH AND CO2 EMISSIONS IN INDONESIA
}

\author{
Azwar Iskandar ${ }^{1}$, Bayu Taufiq Possumah ${ }^{2}$ and Khaerul Aqbar ${ }^{3}$ \\ ${ }^{1}$ Financial Education and Training Agency, Ministry of Finance, Indonesia, azwar@kemenkeu.go.id \\ ${ }^{2}$ Institut Agama Islam Tazkia, Indonesia, btaufiq@gmail.com \\ ${ }^{3}$ Institute of Islamic Studies and Arabic Language, Makassar, Indonesia, khaerul@stiba.ac.id
}

\begin{abstract}
This study examines the dynamic relationship between $\mathrm{CO} 2$ emissions, Islamic financial development and economic growth in Indonesia, using the Environmental Kuznets Curve (EKC) approach over the period 2000-2018. Employing ARDL and ECM testing to examine the existence of long- and short-run relationships between the variables, we found that no EKC's support existence in Indonesia. The study also found no dynamic short-run relationship between growth, Islamic finance development and $\mathrm{CO} 2$ emissions. The long-run findings suggest that $\mathrm{CO} 2$ emissions from transport; other sectors, excluding residential buildings and commercial and public services; and the residential buildings and commercial and public services sectors are significantly associated with Islamic finance development in Indonesia. Hence, the findings of the study show that the country may need to adjust its $\mathrm{CO} 2$ emissions and promote eco-friendly and energy-saving activities to protect nature through Islamic finance development Strength and cost-efficiency.based financial sector development, especially in improved loans for business, would be valuable to limit CO2 emissions.
\end{abstract}

Keywords : Islamic financial development, CO2 emissions, EKC, Growth. JEL Classification : F65; G28; F49.

Article history:

Received : July 24, 2019

Revised : November 2, 2019

Accepted : January 20, 2020

Available online : May 20, 2020

https://doi.org/10.21098/jimf.v6i2.1159 


\section{INTRODUCTION}

\subsection{Background}

In recent times, the Kyoto Protocol (1997) has increased the urgency of many industrialised countries to limit energy use, especially carbon dioxide (CO2). On the other hand, the demand for energy in developing countries has increased significantly along with their economic growth. These two issues make it obligatory for many countries to develop appropriate policies to balance environmental problems, economic growth and energy demand.

Air pollution and income will produce a visible quadratic relation in the long run, a phenomenon commonly referred to as the Environmental Kuznets Curve (EKC) (see Grossman \& Krueger, 1995). Over the last few decades, a number of studies have examined the EKC hypothesis, with mixed results. Once the hypothesis is verifiable, then the implication for an automatic increase in environmental pollution for not doing anything will be objectively real . On the other hand, achieving the Kyoto Protocol ${ }^{1}$ is difficult when air pollution and income do not exhibit mutual U-shaped relationship inversion.

Globalisation through institutional reforms is the main determinant of a country's economic growth and financial development. According to Furuoka (2015), when the government promotes financial development to increase investment, the financial markets will continually accept capital, which leads to increased investment and lower costs. Therefore, the financial and economic activities of a country are closely related since financial development accelerates stock market and banking activities, attracts investment, and stimulates the financial system through improved economy efficiency (Sadorsky, 2011). Financial development develops the financing network and brings financing costs down. Therefore, purchasing a large quantity of new industrial equipment and machinery at lower prices becomes a favourable possibility for the economy. As a consequence, there will be an increase in energy usage and carbon dioxide emissions, meaning the impact of globalisation and financial development on carbon very serious.

In countries with strong economies, an efficient financial sector helps individuals and firms to manage their savings and make investment decisions (Khan, Ali, \& Bhattacharya, 2016). Countries have helped to productively function their limited resources and have encouraged investment activities by allocating funds to productive channels, making capital cheaper, enabling trading, and lifting the domestic output level of firms by using the latest technology (Nasreen \& Anwar, 2016). However, financial development, which plays a vital role in economic growth, directly increases energy consumption levels (Danish, Saud, Baloch, \& Lodhi, 2018), which ultimately increase CO2 emissions (Khan, Yaseen, \& Ali, 2017). For example, financial development helps to cut down the cost of

1 The Kyoto Protocol is based on the principles and provisions of the Kyoto Convention and follows its annex-based structure. The protocol was adopted on 11 December 1997 and only came into force on 16 February 2005 owing to the complex ratification process. Currently, there are 192 parties involved in the protocol, which is operationalised under the United Nations Framework Convention on Climate Change. Even though the convention itself only asks countries to adopt policies and measures on mitigation and to report periodically, industrialised countries have committed to limit and reduce greenhouse gas (GHG) emissions in accordance with agreed individual targets (Kyoto Protocol, 1997. Available online: https://unfccc.int/kyoto_protocol. Accessed on 27 February 2020). 
borrowing, meaning firms are able to buy new machinery and set up new plants. As a result, this increases energy consumption and $\mathrm{CO} 2$ emissions. Likewise, when financial development facilitates customers to buy luxury items which consume high levels of energy, such as houses, cars and air conditioners, this will also result in increased $\mathrm{CO} 2$ emissions.

Several studies have covered the financial development and $\mathrm{CO} 2$ emissions nexus, yet definitive conclusions about the influence of financial sector development on mitigating such emissions can be drawn. From one point of view, Abbasi and Riaz (2016) argue that with financial development the economy improves, investment rises and customer are able to take out loans to buy energy-intensive goods such as cars, air conditioners and refrigerators, which directly cause raised $\mathrm{CO} 2$ emissions.

In addition, stock market development also fundamentally contributes to increased energy consumption and CO2 emissions by lowering the cost of financing, minimising operational risks, improving the asset-to-liability structure, and helping firms set up new plants (Omri, Saida, Rault, \& Chaibi, 2015). In contrast, several studies suggest that financial development lowers $\mathrm{CO} 2$ emissions by introducing energy-efficient modern technologies (Abbasi \& Riaz, 2016). Moreover, financial development which attracts investment is able to advance research and development in producing environmentally-friendly technology and improving environmental quality (Danish et al. 2018; Zhang, 2011). Furthermore, the financial sector, which is able to approve funds for environmentally-friendly projects, will improve the efficiency and quality of life through environmental protection. In addition, the sector can prevent environment damage by giving subsidies to efficient technologies and funding the systematic search for renewable energy sources (Sahbaz et al. 2015) . It is clear that the CO2 emissions and financial development nexus is mixed, since some important determinant variables in previous studies, which should be incorporated into the effect of financial development on $\mathrm{CO} 2$ emissions, are possibly not taken into account .

Recently, researchers' recognition of issues related to Sustainability Development Goals (SDG) goes greater even with quite limited data . On the other hand, there are a limited number of studies on environmental performance and firm profitability in Islamic finance, specifically in the case of Indonesia. This gap has inspired us to study in more depth $\mathrm{CO} 2$ emissions substantial record, as one of the constituents of tSDG index calculations (Mahmood \& Masih, 2019).

Islamic finance principles address the concept that human beings are commissioned as the stewards (khilafah) of God on Earth and are responsible for maintaining the well-being of the environment. Hence, Islamic financial institutions (IFIs) should not overlook their trust (amanah) and responsibility (mas'uliyyah), and this should be reflected in their investments and financial activities. IFI responsibilities primarily involve working to fulfil a collective social and religious obligation (fard kifayah) for their various stakeholder groups. Second, IFIs have a social responsibility to effectively and efficiently mobilise resources for the benefit of the community. Islam, and in particular Shari'ah, which incorporates Islamic financial jurisprudence, or figh al-mu'amalat, strongly emphasises the ethical, environmental and social impacts on stakeholders. In the Qur'an, the primary source of Islamic law, there are around five hundred verses which describe and 
praise the environment and moreover urge people to look after it (Bakar, 2007). The teachings of the Prophet Muhammad (peace be upon him), known as the hadith, another primary source of Islamic law, elaborate on governance, ethics, the environment and waste management, besides kindness to human beings and all other creations (Kamali, 2012).

Many developing countries today are suffering from greater environmental problems as a consequence of the higher energy consumption needed for greater economic development. The environmental pollution issue is thus becoming progressively important. As a developing country, Indonesia faces similar problems to other such countries. It is a useful case study for several reasons, especially in relation to the Islamic financial development and $\mathrm{CO} 2$ emissions nexus. First, because of the potential expenditure of Muslim consumers on various consumer products, along with the increasing purchasing power of the Muslim world, several global institutions got attention by global institution such as Thomson Reuters, Islamic economic and finance sector began concerned throughout the world . Indonesia, as the biggest Muslim consumer of Islamic economic products in the international market and as a member of the G20, contributes greatly to world GDP levels. In this sense, it is undeniable that Indonesia is part of the international Muslim community, and has also helped to shape global Islamic economic trends.

The Global Economic Report (2018/2019) reported that total Muslim expenditure in 2017 was approximately USD 2.1 trillion, which is around $0.27 \%$ of global total gross product. The report derives consumption expenditure from several halal products, such as food, pharmaceuticals and cosmetics, travel, media and fashion. This potential is expected to increase in line with the growth of the world's Muslim population.

Second, Indonesia, as the world's fourth largest greenhouse gas (GHG) emitter, has committed to significant voluntary actions and is now leading the way by cutting its national greenhouse gas emissions by $26 \%$ (unilaterally) and by $41 \%$ by 2020 (with support from the international community).

Third, it could be argued that Indonesia is playing a strategic role and has an important responsibility as a middle-income country in balancing emissions reduction priorities and economic development (EDC2020, 2019) ${ }^{2}$. Fourth, with approximately 2000 out of 17000 islands (archipelagic state), Indonesia is vulnerable to climate change. Indonesia is predicted to be submerged by 2030 if the current trend of global warming continues unabated (Iskandar, 2019).

\subsection{Objective}

Based on the above discussion, this empirical study aims to examine the dynamic relationship between $\mathrm{CO} 2$ emissions, Islamic financial development and economic growth, from the perspective of the EKC hypothesis.

To achieve this objective, the paper is methodically arranged as follows: Section 2 presents the literature review; Section 3 describes the methodology employed, including the data and model; Section 4 discusses the empirical results; and Section 5 presents the conclusion and policy implications.

2 http://www.edc2020.eu/117.0.html 


\section{LITERATURE REVIEW}

Many studies have assessed the relationship between economic or firm performance and environmental factors; for example Sandeep and Bedi (2016), and Hidayat, Akhmad, and Mu'alim (2015). In this section, to gain a holistic understanding of the study issues, various arguments from theoretical and empirical findings will be explored.

\subsection{Background Theory}

The Environmental Kuznets Curve (EKC) hypothesises that there is interdependence between environmental quality and economic development. Through an inverted U-shaped relationship between income and $\mathrm{CO} 2$, the curve suggests that the early phase of economic development initially leads to a deterioration in the environment, but after a certain level of economic growth, society begins to improve its relationship with the environment and the level of environmental degradation is reduced. Finally, at a certain point, economic development starts to reduce CO2 emissions (Grossman \& Krueger, 1995; Shafik \& Bandyopadhyay, 1992). However, since it is not a question of policy prevention, it is important to apply the EKC hypothesis to the turning point of negative $\mathrm{CO} 2$ as an effect of economic progress .

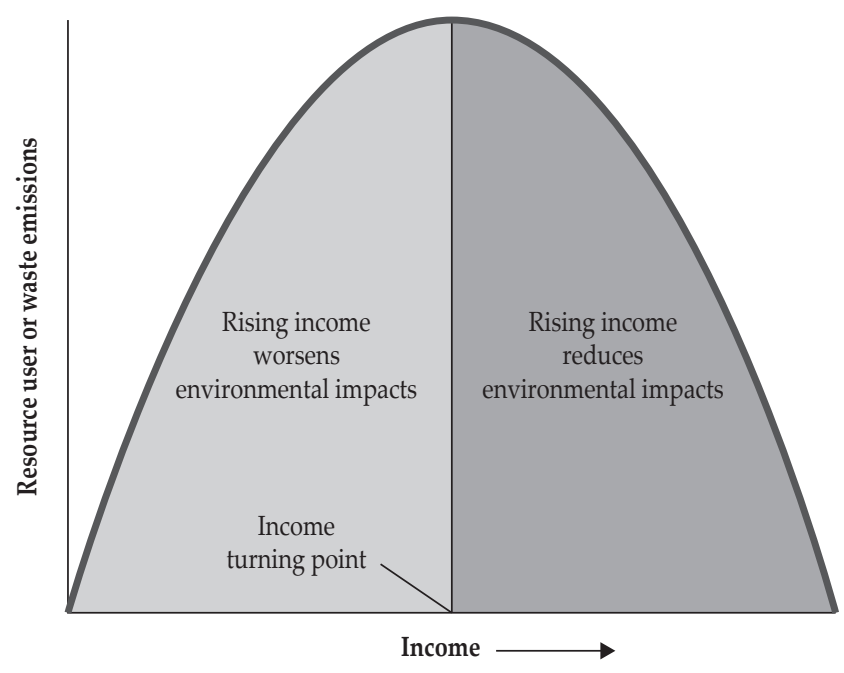

Source : Mahmood and Masih (2019)

Figure 1.

The Environmental Kuznets Curve Model

Referring to Grossman and Krueger (1995), the possibility of an inverted U-shaped relationship between environmental pollution and economic growth is based on three different aspects: the scale effect, composition effect and technique effect. With regard to the scale effect, economic growth impacts the environment 
negatively. Increased production and economic growth then cause environmental degradation, increased pollution and positively composition impacts environment.

Pollution increases in the early stages, along with changes in a country's economic structure from mainly agricultural production to more resourceintensive heavy manufacturing industries. Subsequently, in the later stages of development, pollution decreases as the structure shifts towards service and light manufacturing industries. In the final (decline) stages, along with economic growth, technique effect suggests that obsolete technologies are replaced by new environmentally-friendly ones. As a result, environmental quality is improved. According to Stern (2004), the EKC shows that the negative impacts of scale effects on the environment mostly dominate in the initial stages of economic growth, while the positive impacts of composition and technique effects on decreasing emissions levels take place in the decline stage

\subsection{Previous Studies}

A study by Tiwari and Nasir (2013) on the EKC hypothesis in South Africa proposed that emissions decreased in the domestic credit for long- and short-run to private sector . With regard to the effects of $\mathrm{CO} 2$ emissions and financial development in an emerging economy, using the augmented VAR approach, Abbasi and Riaz (2016) found that economic growth and financial sector development caused an increase in energy consumption, which then ultimately led to higher emissions and to reduced liquidity constraints impacted by the increased development of the stock market. In the short run, Abbasi and Riaz found that growth in per capita income and private sector loans also resulted in higher $\mathrm{CO} 2$ emissions.

Riaz (2016) highlighted that changes in the size and structure of the financial sector were one of the factors that reduced green technology adoption. To elaborate, as the financial sector starts to grow, so does the stock market. In fact, the stock market has greater significance than the banking sector. This is an example of structural transformation that may affect $\mathrm{CO} 2$ emissions, although the literature is inconclusive on the subject.

Studies that have examined the relationship between financial development and CO2 emissions include that of Tamazian, Piñeiro, and Vadlamannat (2009), who focused on the impact of economic and financial development on $\mathrm{CO} 2$ emissions in BRIC nations together with the United States and Japan, and found that both were determinant factors in reducing $\mathrm{CO} 2$ emissions. They also found that trade liberalisation and financial sector reforms helped to reduce $\mathrm{CO} 2$ emissions. Tamazian and Rao (2010), who applied the GMM approach to ascertain the effects of institutional, economic and financial developments on $\mathrm{CO} 2$ emissions in transitional economies, found that these factors helped to reduce $\mathrm{CO} 2$ emissions and also found support in favour of the EKC.

Islam et al. (2019) confirmed the short- and long-run relationships between $\mathrm{CO} 2$ emissions and financial development in Malaysia, with findings in line with those of Boutabba (2014) in India. Omri et al. (2015) empirically found that financial development was damaging for the environment in the long-run and suggested a neutral relationship between financial development and $\mathrm{CO} 2$ emissions in 12 MENA (Middle East and North Africa) countries. In addition, Abbasi and Riaz 
(2016) found that mitigation of CO2 emissions in small emerging economies was affected by role of financial development.

Mallick et al. (2016) found that financial development was disadvantageous for environmental quality in Pakistan, while Bekhet, Matar, and Yasmin (2017) confirmed that the high $\mathrm{CO} 2$ emissions in all the Gulf Cooperation Council (GCC) countries, apart from the United Arab Emirates (UAE), were influenced by financial development. Kahouli (2017) found undirectional causality between $\mathrm{CO} 2$ emissions and financial development in South Mediterranean countries (SMCs). The findings of Khan, Saleem, and Fatima (2017) suggest that financial development reduced CO2 emissions in Pakistan and Bangladesh, but not in India. Khan, Yaseen, and Ali (2017) confirmed bidirectional causality between CO2 emissions and financial development in Asia, while Riti et al. (2017) concluded that financial development reduced CO2 emissions in 90 countries. Finally, empirical analysis by Salahuddin et al. (2017) suggested that financial development did not account for $\mathrm{CO} 2$ emissions in Kuwait.

According to the previous studies, from the economic development and $\mathrm{CO} 2$ emissions perspective some conflicting issues arise. On the one hand, some argue that $\mathrm{CO} 2$ emissions increase when there is a reduction in credit constraints. In other words, when economic output expands, energy consumption or CO2 emissions will ultimately be higher (Abbasi \& Riaz, 2016). On the other hand, it is also argued that financial sector development actually contributes to increased investment in green technology. For instance, attracting higher foreign direct investment can be channeled to more efficient technologies, thus ultimately reducing $\mathrm{CO} 2$ emissions (Frankel \& Romer, 2017). Evidently, the conflicting findings reflect mixed results on the relationship between economic development and $\mathrm{CO} 2$ emissions.

\section{RESEARCH METHODOLOGY}

\subsection{Data}

In this study, carbon-dioxide (CO2) emissions are the dependent variable, while Islamic financial development, economic growth and the square of GDP are the independent variables.

Annual data from 2000-2018 were employed. CO2 emissions were measured in metric tons and categorised into five types: (1) those from transportation; (2) those from other sectors, excluding residential buildings and commercial and public services; (3) those from manufacturing industries and construction; (4) those from electricity and heat production; and (5) those from residential buildings and commercial and public services . Domestic credit to the private sector (Salahuddin et al., 2017) was used a proxy to measure financial development. The focus was on Islamic domestic credit, not only from sharia commercial banks, but also sharia business units, as this indicator measures the role of financial institutions in channeling funds to users in bank-based business. Bank-based and marketbased financial indicators exist to measure financial development. This paper used banking sector development as the model and Islamic domestic credit (financing) as a proxy for Islamic financial development (Clarke, Xu, \& Zou, 2003; Islam, 2011, amongst others). The study also uses GDP per capita (constant LCU). Time series data were retrieved from the World Bank World Development Indicators (WDI) online database and Statistics Indonesia (BPS). 


\subsection{Model Development}

Following Halicioglu (2009), the study specified the following linear logarithmic quadratic functional form for the long-run relationship between carbon emissions, economic growth and national exports and imports. According to the EKC hypothesis, a non-linear quadratic association exists between pollution and income, formulated as follows:

$$
E=\varnothing_{0}+\alpha_{1} Y_{t}+, \alpha_{2} Y_{t}^{2}+\alpha_{3} I F D_{t}+\alpha_{4} Z_{t}+\varepsilon_{t}
$$

where $\mathrm{E}$ refers to environmental degradation; $\mathrm{Y}$ is growth; $\mathrm{Y}^{2}$ is the square of growth; IFD is Islamic financial development; and $\mathrm{Z}$ represents other descriptive variables that may influence environmental degradation. $\mathrm{CO} 2$ emissions have been widely used as a dependent variable (Al-mulali \& Saboori, 2015; Lau, Choong, \& Kee, 2014; Osabuohien, Efobi, \& Gitau, 2014). If the EKC hypothesis holds, the expected sign of $\alpha_{1}$ is significantly positive and $\alpha_{2}$ is significantly negative. The statistical significance of $\alpha_{2}$ implies a monotonically increasing relationship between carbon emissions and income. All the series were converted into natural logarithm (Ln) form for consistent and reliable results. The log-linear specification provides better results because the conversion of the series into logarithm form reduces the sharpness in time series data (Rehman, 2014).

The term 'economic growth' is widely used to describe economic development. Moreover, it incorporates the EKC hypothesis. Furthermore, several studies have employed imports and exports as an indicator to trade, such as those of Al-mulali et al. (2015) and Osabuohien et al. (2014).

The Autoregressive Distributed Lag approach (ARDL) bound testing (Pesaran, Smith, \& Shin (2001)) employed in this study has several advantages over alternatives. For instance, it can be applied to both stationary and integrated variables in a different order, hence overcoming the integration order problem, as discussed by Johansen \& Juselius (1990). Heterogeneity and mitigates serial correlation problems redressed through accurate order augmentation of the repressor and appropriate lag selection. The model can be identified as follows:

$$
\begin{aligned}
& \Delta \operatorname{LnCOT}_{t}=\beta_{0}+\sum_{i=1}^{n} a_{1} \Delta L n C O T_{t-1}+\sum_{i=1}^{n} a_{2} \Delta \operatorname{LnGDP} P_{t-1}+\sum_{i=1}^{n} a_{3} \Delta L n G D P_{t-1}^{2} \\
& +\sum_{i=1}^{n} a_{4} \Delta L n I F D_{t-1}+\beta_{1} \Delta L n C O T_{t-1}+\beta_{2} \Delta L n G D P_{t-1}+\beta_{3} \Delta L n G D P_{t-1}^{2} \\
& +\beta_{4} \Delta L n I F D_{t-1}+\theta E C T_{t-1}+\varepsilon_{t} \\
& \Delta \operatorname{LnCOO}_{t}=\beta_{0}+\sum_{i=1}^{n} a_{1} \Delta \operatorname{LnCOO}_{t-1}+\sum_{i=1}^{n} a_{2} \Delta \operatorname{LnGDP} P_{t-1}+\sum_{i=1}^{n} a_{3} \Delta \operatorname{LnGDP}_{t-1}^{2} \\
& +\sum_{i=1}^{n} a_{4} \Delta \operatorname{LnIFD}_{t-1}+\beta_{1} \Delta \operatorname{LnCOO} t-1+\beta_{2} \Delta L n G D P_{t-1}+\beta_{3} \Delta L n G D P_{t-1}^{2}
\end{aligned}
$$

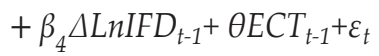




$$
\begin{aligned}
& \Delta \operatorname{LnCOM}_{t}=\beta_{0}+\sum_{i=1}^{n} a_{1} \Delta \operatorname{LnCOM} \mathrm{C}_{t-1}+\sum_{i=1}^{n} a_{2} \Delta \operatorname{LnGDP} P_{t-1}+\sum_{i=1}^{n} a_{3} \Delta \operatorname{LnGDP}_{t-1}^{2} \\
& +\sum_{i=1}^{n} a_{4} \Delta L n I F D_{t-1}+\beta_{1} \Delta L n C O M_{t-1}+\beta_{2} \Delta L n G D P_{t-1}+\beta_{3} \Delta L n G D P^{2} t \\
& +\beta_{4} \Delta \operatorname{LnIFD} D_{t-1}+\theta E C T_{t-1}+\varepsilon_{t} \\
& \Delta \operatorname{LnCOE} E_{t}=\beta_{0}+\sum_{i=1}^{n} a_{1} \Delta \operatorname{LnCOE} E_{t-1}+\sum_{i=1}^{n} a_{2} \Delta \operatorname{LnGDP} P_{t-1}+\sum_{i=1}^{n} a_{3} \Delta \operatorname{LnGDP}_{t-1}^{2}
\end{aligned}
$$

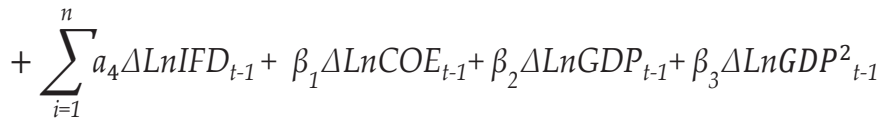

$$
\begin{aligned}
& +\beta_{4} \Delta \operatorname{LnIFD} D_{t-1}+\theta E C T_{t-1}+\varepsilon_{t} \\
& \Delta \operatorname{LnCOB}{ }_{t}=\beta_{0}+\sum_{i=1}^{n} a_{1} \Delta \operatorname{LnCOB} t-1+\sum_{i=1}^{n} a_{2} \Delta \operatorname{LnGDP} t-1+\sum_{i=1}^{n} a_{3} \Delta \operatorname{LnGDP^{2}}{ }_{t-1} \\
& +\sum_{i=1}^{n} a_{4} \Delta \operatorname{LnIFD}_{t-1}+\beta_{1} \Delta \operatorname{LnCOB}_{t-1}+\beta_{2} \Delta \operatorname{LnGDP_{t-1}}+\beta_{3} \Delta L n G D P^{2}{ }_{t-1} \\
& +\beta_{4} \Delta \operatorname{LnIFD_{t-1}}+\theta E C T_{t-1}+\varepsilon_{t}
\end{aligned}
$$

where $\mathrm{COT}$ is $\mathrm{CO} 2$ emissions from transport; $\mathrm{COO}$ is $\mathrm{CO} 2$ emissions from other sectors, excluding residential buildings and commercial and public services; $\mathrm{COM}$ is $\mathrm{CO} 2$ emissions from manufacturing industries and construction; $\mathrm{COE}$ is $\mathrm{CO} 2$ emissions from electricity and heat production; $\mathrm{COB}$ is $\mathrm{CO} 2$ emissions from residential buildings and commercial and public services ; GDP is GDP per capita; and IFD is Islamic finance development.

From these equations, $\Delta$ is the first difference of the logged variables, and $t$ and $\varepsilon_{\mathrm{t}}$ severally represent time period and white noise. $\theta \mathrm{ECT}_{\mathrm{t}-1}$ in equations (2) - (6) relates to the error correction term (ECT). This shows how rapidly the variables return to long-run equilibrium and demonstrates the speed of the adjustment. $a_{i^{\prime}}$ where $i=1,2,3,4$, stands for the corresponding short-run multipliers, while parameters $\beta_{i}$, where $i=1,2,3,4$, represents the long-run dynamic coefficients of the fundamental ARDL model. A linear combination of lagged-level variables is included as an intermediary for lagged error terms in the equation as a standard vector auto regression (VAR) model.

\subsection{Method}

The study originally examined the unit root of all the variables using both the Augmented Dickey-Fuller (ADF) and Phillips-Perron (PP) tests. Subsequent to checking for the unit root, it was then possible to utilise either the Johansen \& Juselius (1990) or the Engle Granger cointegration test if the arrangement of each 
variable was integrated of the same order. The ARDL approach was applied to deal with the test for cointegration, as the Johansen method requires the variables to be coordinated in the same order, which was not the case in this study. In any other way the predictive power of the models examined would be affected.

The ARDL approach developed by Pesaran, Smith, \& Shin (2001) handles these issues, as it can be applied regardless of whether the variables are $\mathrm{I}(0)$ and/ or I(1). Moreover, significantly, the Johansen approach is not appropriate for this study, as it deals with small sample time arrangements. On the other hand, ARDL provides powerful outcomes even with small samples (Pesaran, 1997) and is thus beneficial, as imbalanced income data is only available for annual data, and the periods available are likewise constrained for many emerging economies such as Indonesia. In addition, ARDL allows the ideal lag lengths for the variables to vary, which makes it more advantageous, while the Johansen approach necessitates all the variables in the model to have the same number of lags. In this study, the AIC (Akaike Information Criterion) was employed to determine the optimal lag lengths for the ARDL model.

In particular, it was discovered that in certain models, the Schwarz Bayesian Criterion $(\mathrm{SBC})$ ran the models with $\operatorname{ARDL}(0,0,0,0)$ to such an extent that no ECM statistical outcome was produced, even though the SBC gave least standard errors to a portion of our models examined under ARDL. This is due to the SBC method of choosing the minimum lag possible, so accordingly it was realised that the AIC was more appropriate for this study.

The first step in ARDL is to empirically investigate the presence of long-run relationships between the variables. At this point, the determined F-statistic is compared against the upper and lower critical bounds provided by Pesaran, Smith, \& Shin (2001), which relate to the presumption that the variables are $\mathrm{I}(0)$ and $\mathrm{I}(1)$ separately. If the calculated F-statistics surpass the upper critical bound (UCB), then the arrangements are cointegrated; otherwise, if they are below the lower critical bound (LCB), there is no cointegration. In the event that the calculated F-statistics are between the UCB and the LCB, any decision on cointegration is uncertain and knowledge of the cointegration rank of the forcing variables is required for further processing.

In the following hypotheses, $\mathrm{H}_{0}: \delta 1=\delta 2=\delta 3=\delta 4=0$ is examined using the ARDL cointegration test and states that there is no long-run relationship between the variables. $H_{a}: \delta 1 \neq \delta 2 \neq \delta 3 \neq \delta 4 \neq 0$ shows that there is cointegration or a longrun relationship between them .

In the second step, the long-run coefficients and the error correction term (ECT) can be predicted when cointegration between the variables has been set up. The ARDL cointegration procedure allows the cointegrating relationship to be assessed by OLS once the lag order is chosen.

Through a simple linear transformation, by which the dynamic error correction model (ECM) fuses the short-run dynamics with long-run equilibrium, the ECM is obtained from the ARDL model, without losing long-run information. Causality in the previous step will be examined and affirmed through the t-statistic of the ECM. In addition, the coefficient of the ECM shows the speed of adjustment of the dependent variable towards its long-run equilibrium. The endogeneity or exogeneity of the variable is tested through the ECM, and a similar equation is 
utilised with each proxy of corruption and poverty thus being the reliant variable . The hypothesis is tested by the ECM as follows: $\mathrm{H}_{0}$ : the variable is exogeneous, and $\mathrm{H}_{\mathrm{a}}$ : the variable is endogenous.

\section{RESULTS AND ANALYSIS}

\subsection{Results}

The unit root test provides direction to establish whether ARDL is appropriate or not, since it is only applicable to the analysis of variables that are integrated to order zero $[\mathrm{I}(0)]$ or order one $[\mathrm{I}(1)]$, and not to higher orders of integration, such as I(2). Examining the stationarity of variables is essential to avoid spurious regression. Therefore, the Augmented Dickey-Fuller (ADF) test of Dickey \& Fuller (1979) and the Phillips-Perron (PP) test of Phillips \& Perron (1986) technique were used to investigate the stationarity of the variables. The results of the two tests with trends and intercepts are shown in Table 1.

Table 1.

Results of the ADF and PP tests

\begin{tabular}{lcccc}
\hline \multicolumn{5}{c}{ Level } \\
\hline Variable & t-statistic & Prob. & t-statistic & Prob ${ }^{*}$ \\
COT & -17.21782 & $0.0001^{*}$ & -2.450787 & 0.1469 \\
COO & -3.032318 & $0.0561^{* * *}$ & -3.589361 & $0.0211^{* *}$ \\
COM & -3.836651 & $0.0135^{* *}$ & -3.915774 & $0.0117^{* *}$ \\
COE & -4.146776 & $0.0078^{*}$ & -4.645686 & $0.0032^{*}$ \\
COB & -1.587815 & 0.4622 & -1.581442 & 0.4653 \\
GDP & 1.604661 & 0.9987 & 1.412038 & 0.9979 \\
GDP & -2.201986 & 0.2132 & -2.201986 & 0.2132 \\
IFD & -1.652970 & 0.4299 & -3.997762 & $0.0101^{* *}$ \\
\hline & & $1^{\text {st }}$ Difference & & \\
\hline COT & -10.32514 & $0.0000^{*}$ & -6.005178 & $0.0004^{*}$ \\
COO & -3.552841 & $0.0256^{* *}$ & -7.566130 & $0.0000^{*}$ \\
COM & -5.743285 & $0.0006^{*}$ & -11.23084 & $0.0000^{*}$ \\
COE & -5.794016 & $0.0006^{*}$ & -12.47909 & $0.0000^{*}$ \\
COB & -3.667847 & $0.0196^{* *}$ & -3.668640 & $0.0196^{* *}$ \\
GDP & -3.670012 & $0.0211^{* *}$ & -3.550788 & $0.0213^{* *}$ \\
GDP 2 & -11.53229 & $0.0000^{*}$ & -9.794778 & $0.0000^{*}$ \\
IFD & -3.120642 & $0.0499^{* *}$ & -3.054086 & $0.0559^{* *}$ \\
\hline
\end{tabular}

* Significant at the $1 \%$ level; ${ }^{* *}$ significant at the $5 \%$ level. \# MacKinnon (1996) one-sided p values . Source: Author's calculations.

Invalid speculation of the unit root issue is rejected at the initial distinction. This demonstrates that most variables are acknowledged to be stationary at level, implying that they are integrated at $\mathrm{I}(0)$; those applied in this study were not all integrated of the same order. Therefore, the ARDL approach was employed to deal with co-integration test. 
Once the stationarity of the variables is confirmed, testing the co-integration between the variables is conducted. In this way, the ARDL bounds testing approach is employed to test the existence of long-run relationships. In order to do this, however, it is essential to recognise a proper lag length to calculate the F-statistics. The ARDL model is sensitive to lag order. Moreover, ideal lag order would be useful in reliable and consistent result in the analysis. Therefore, the Akaike Information Criterion (AIC) can be considered to obtain the ideal lag length. The decision to use this criterion depends on the stricter penalties imposed by it (see Table 2), as it gives better and more consistent outcomes compared to other lag length criteria (Uddin, Arouri, \& Teulon, 2014).

Table 2.

Model Selection Criteria

\begin{tabular}{lcccccc}
\hline Model & LogL & AIC* & BIC & HQ & $\begin{array}{c}\text { Adj. } \\
\text { R-sq }\end{array}$ & Specification \\
\hline $\mathrm{COT}=\mathrm{f}\left(\mathrm{Y}, \mathrm{Y}^{2}, \mathrm{IFD}\right)$ & 18.602237 & -2.291316 & -2.074282 & -2.428125 & 0.869007 & ARDL $(1,0,0,1)$ \\
$\mathrm{COO}=\mathrm{f}\left(\mathrm{Y}, \mathrm{Y}^{2}, \mathrm{IFD}\right)$ & -0.830098 & 1.423654 & 1.676860 & 1.264043 & 0.765642 & ARDL $(1,0,1,1)$ \\
$\mathrm{COM}=\mathrm{f}\left(\mathrm{Y}, \mathrm{Y}^{2}, \mathrm{IFD}\right)$ & -11.140062 & 3.116375 & 3.333409 & 2.979565 & 0.255688 & ARDL $(1,0,1,0)$ \\
$\mathrm{COE}=\mathrm{f}\left(\mathrm{Y}, \mathrm{Y}^{2}, \mathrm{IFD}\right)$ & -4.616726 & 2.112132 & 2.365338 & 1.952521 & 0.188911 & ARDL $(1,1,0,1)$ \\
$\mathrm{COB}=\mathrm{f}\left(\mathrm{Y}, \mathrm{Y}^{2}, \mathrm{IFD}\right)$ & 1.431047 & 0.830719 & 1.047753 & 0.693909 & 0.719697 & ARDL $(1,0,0,1)$ \\
\hline
\end{tabular}

Source: Author's calculations.

The variables were tested for cointegration after stationary tests on them and choice of the lag optimum for the model was made by applying the ARDL bound testing approach to test the null against the no long-run (LR) relationship among the variables. The enumerated F-statistic was compared with the upper and lower critical bounds generated by Pesaran et al. (2001) to test for the presence of cointegration. The invalid speculation is $\mathrm{H}_{0}: \lambda_{j}=0$ (where $\left.\mathrm{j}=1,2, \ldots, 4\right)$ in equation (4). This infers no long-run relationship between the variables, against the elective speculation, $\mathrm{H}_{1}: \lambda_{j} \neq 0$, thus inferring the existence of long-run relationships between the variables .

The results shown in Table 3 indicate that all the computed F-statistics on models are greater than the upper bound (5.61) at several levels of significance. All the models suggest that there is proof to dismiss the invalid hypothesis of no long-run relationships among the variables. Therefore, the acknowledged elective speculation is a long-run equilibrium relationship between $\mathrm{CO} 2$ emissions, growth, and Islamic finance development in all the models. 
Table 3.

Result of Bounds Testing

\begin{tabular}{lcc}
\hline Estimation & F-statistic & Result \\
\hline Model 1 FCOT [COT $\mid$ Y, $\mathrm{Y}^{2}$, IFD] & $61.804^{*}$ & Co-integration \\
Model 2 FCOO [COO $\mid$ Y, $\mathrm{Y}^{2}$, IFD] & $13.684^{*}$ & Co-integration \\
Model 3 FCOM [COM $\mid$ Y, Y ${ }^{2}$, IFD] & $5.615^{*}$ & co-integration \\
Model 4 FCOE [COE $\mid \mathrm{Y}, \mathrm{Y}^{2}$, IFD] & $4.558^{* *}$ & Co-integration \\
Model 5 FCOB [COB $\mid \mathrm{Y}, \mathrm{Y}^{2}$, IFD] & $6.401^{*}$ & Co-integration \\
\hline Critical values for F-statistics (\%) & Lower I $(0)$ & Upper I $(1)$ \\
\hline $10 \%$ & 2.72 & 3.77 \\
$5 \%$ & 3.23 & 4.35 \\
$2.5 \%$ & 3.69 & 4.89 \\
$1 \%$ & 4.29 & 5.61 \\
\hline
\end{tabular}

* Significant at the $1 \%$ level; ${ }^{* *}$ significant at the $5 \%$ level.

Source: Author's calculations.

A long-run relationship between $\mathrm{CO} 2$ emissions and their determinants depends on the bound testing approach, which allows us to estimate long- and short-run models of environmental degradation in Indonesia. In order to verify the EKC hypothesis, long- and short-run models were compared. Tables 4 and 5 show the results of the comparison..

\subsection{Robustness Test}

In order to show the short- and long-run impact of Islamic finance development on the level of $\mathrm{CO} 2$ emissions, the error correction model (ECM) related to ARDL was evaluated. In addition, the ECM involves the short-run transitory effects and the long-run relationships; the speed of adjustment of the dependent variable to changes in the independent variables is also decided within the framework make the fact strengthen (see Table 4 and 5 below).

Table 4.

Results of the Short-Run Error Correction Model (ECM)

\begin{tabular}{lcccccccccc}
\hline \multirow{2}{*}{$\begin{array}{l}\text { Independent } \\
\text { Variable }\end{array}$} & \multicolumn{2}{c}{ Model 1 } & \multicolumn{2}{c}{ Model 2 } & \multicolumn{2}{c}{ Model 3 } & \multicolumn{2}{c}{ Model 4 } & \multicolumn{2}{c}{ Model 5 } \\
\cline { 2 - 11 } & Coeff. & Prob. & Coeff. & Prob. & Coeff. & Prob. & Coeff. & Prob. & Coeff. & Prob. \\
\hline $\mathrm{D}(\mathrm{Y})$ & 1.166 & 0.798 & 64.527 & 0.465 & 92.090 & 0.417 & -17.317 & 0.819 & 74.524 & 0.098 \\
$\mathrm{D}\left(\mathrm{Y}^{2}\right)$ & -0.781 & 0.731 & -31.361 & 0.474 & -47.200 & 0.403 & 9.768 & 0.795 & -37.778 & 0.090 \\
$\mathrm{D}(\mathrm{IFD})$ & 0.513 & 0.242 & -6.341 & 0.420 & -2.760 & 0.778 & -4.721 & 0.496 & -1.500 & 0.666 \\
$\mathrm{ECM}(-1)$ & -0.070 & 0.614 & -1.583 & 0.550 & -4.042 & 0.256 & 0.148 & 0.948 & -1.686 & 0.189 \\
\hline
\end{tabular}

Sourc: Author's calculations.

The ECM results in Table 4 show the short effect of growth and Islamic finance development on $\mathrm{CO} 2$ emissions. From the p-value (Prob.) of error correction (ECM $(-1))$ in the table (with $1 \%, 2.5 \%$, and $5 \%$ significance levels), it can be concluded that in the short-run, Islamic finance development, growth and $\mathrm{CO} 2$ 
emissions are not endogenous for all models. None of these variables is dependent on other variables, which helps the argument that there is no dynamic relationship in the short-run between growth, Islamic finance development and CO2 emissions in several sectors, such as transport.

Table 5.

Results of ARDL Estimation Based on AIC for Long Run

\begin{tabular}{lccccc}
\hline Variable & Model 1 & Model 2 & Model 3 & Model 4 & Model 5 \\
\hline \multirow{2}{*}{$\mathrm{Y}$} & 4.20 & -39.073 & 7.256 & -54.802 & 31.186 \\
& {$[0.567]$} & {$[0.173]$} & {$[0.942]$} & {$[0.193]$} & {$[0.299]$} \\
\hline \multirow{2}{*}{$\mathrm{Y}^{2}$} & -2.363 & 21.220 & -6.486 & 27.786 & -14.325 \\
& {$[0.518]$} & {$[0.148]$} & {$[0.897]$} & {$[0.185]$} & {$[0.341]$} \\
\hline \multirow{2}{*}{$\mathrm{IFD}$} & 0.41 & -1.647 & 2.363 & -0.594 & -1.128 \\
& {$[0.032]^{* *}$} & {$[0.081]^{* * *}$} & {$[0.305]$} & {$[0.601]$} & {$[0.045]^{* *}$} \\
\hline
\end{tabular}

** Significance at $5 \%$ level, ${ }^{* * *}$ Significance at $10 \%$ level

Source : Author's Calculation

In all the long-run models (Table 5), growth $(Y)$ and the square of growth $\left(Y^{2}\right)$ do not appear to have a significant effect on $\mathrm{CO} 2$ emissions. The long-run findings suggest that $\mathrm{CO} 2$ emissions from transport; other sectors, excluding residential buildings and commercial and public services; and residential buildings and commercial and public services are essentially related to Islamic financial growth in Indonesia. On the other hand, $\mathrm{CO} 2$ emissions from all sectors are indicated to be irrelevant to monetary development in the country.

\subsection{Analysis}

Table 5 shows the long-run estimates for Indonesia and indicates that Islamic financial development and energy consumption have a positive and negative relationship based on $\mathrm{CO} 2$ emission resources . Islamic financial development has a positive impact on $\mathrm{CO} 2$ emissions from transport with a coefficient value of 0.41 . A $1 \%$ increase in Islamic finance development will increase CO2 emissions from transport with the percentage of 0.41 . This infers that carbon emissions increase with a rise in Islamic monetary growth and energy consumption. The Indonesian government should take effective measures to develop energy saving projects for energy efficiency by expanding Islamic financial development, but financial institutions must develop strict policies for organisations to utilise Islamic domestic credit in their low carbon emission projects. Additionally, they could also hold seminars to build awareness amongst people in urban areas of the impacts of high carbon emissions. Islamic financial improvement, however, negatively affects $\mathrm{CO} 2$ emissions from private structure and commercial and public services, with coefficient values of -1.647 and -1.128 respectively. This suggests that with the expansion of Islamic finance, carbon emissions decrease in Indonesia.

In the case of Indonesia, the observational outcomes do not support the legitimacy of EKC. In this regard, any control of CO2 emissions must reasonably inferred, and suitable policies may be supported to efficient energy consumption. 
The Islamic financial sector can play its role in protecting the environment by empowering environmentally-friendly and energy-efficient projects. A strong and proficient budgetary sector would be useful in encouraging ventures by advancing loans for business on the condition of controlling carbon dioxide emissions.

There is evidence of no EKC hypothesis in all models provided short-run and long-run computed models (Tables 4 and 5). Moreover, regardless of the source of $\mathrm{CO} 2$ emissions, whether from transport; other sectors, excluding residential buildings and commercial and public services; manufacturing industries and construction; electricity and heat production; and residential buildings and commercial and public services (Models 1, 2, 3, 4, and 5), the EKC hypothesis is problematic.

The evaluated outcomes are in line with other studies, for instance Jalil and Mahmud (2009) and Saboori, Sulaiman, and Mohd (2012). A potential reason for the unsuitability of the EKC hypothesis in Indonesia for all sources of CO2 emissions is that the economy of Indonesia is still resource escalated instead of servicesbased, with services contributing $45.9 \%$ of total GDP per capita in 2017 , while the agriculture and industry sectors contributed $13.9 \%$ and $40.3 \%$ respectively (Index Mundi, 2018) ${ }^{3}$. Agriculture includes farming, fishing and forestry, while industries include mining, manufacturing, energy production, and construction. Services include government activities, communications, transportation, finance, and all other private economic activities that do not produce material goods.

Economic growth and advancement is a key objective for most emerging nations in their quest to be completely evolved nations. At the same time, financial expansion typically causes environmental degradation. Subsequently, it is essential for policymakers to develop appropriate policies regarding the halting of environmental degradation, without harming economic development in the country.

In reality, there is a connection between $\mathrm{CO} 2$ emissions and Islamic finance improvement, and their long-run relationship is significant. Several policy implications arise as a result of the study findings. At the point when $\mathrm{CO} 2$ emissions rise, the economy's carbon footprint expands. Policymakers can use the patterns concentrated in this study to develop policies that urge Islamic banks to protect the environment. It is also essential to keep in mind that emerging economies will in general face structural transformation. Money related advancement for the most part contributes to increasing emissions, rather than reducing them, which is different to the situation of financing in developed countries.

The study topic in this research is extremely under-investigated and there are many related areas that are worth exploring. Islamic finance is not only about guaranteeing Shariah-compliant item structures, but it also needs to consider the general effect on the public. Policymakers should consider this when encouraging Islamic banks to be more naturally aware completely. This study provides unique insights into the links between Islamic finance development and $\mathrm{CO} 2$ emissions, which can help policymakers make effective decisions. The finance sector can play its role in maintaining the environment by empowering environmentally-friendly and energy-efficient projects. A strong and proficient financial sector would

3 https://www.indexmundi.com/indonesia/gdp_composition_by_sector.html 
help in encouraging ventures by propelling household credit for business on the condition of controlling carbon dioxide emissions.

\section{CONCLUSION AND RECOMMENDATIONS}

\subsection{Conclusion}

The ecological pollution issue is a dynamic one in developing countries, as they require more energy to encourage greater financial development. Subsequently, such countries experience the ill effects of ecological issues. Clearly, as a developing nation, Indonesia is facing the same issues as other developing countries. This research has analysed the dynamic connections between Islamic financial development, monetary growth, and $\mathrm{CO} 2$ emissions in relation to the EKC hypothesis.

The results show that in the short-run, Islamic finance development, growth and $\mathrm{CO} 2$ emissions are not endogenous for all models. All the variables are not dependent on other variables, which helps the argument that there is no dynamic relationship in the short run between growth, Islamic finance development and $\mathrm{CO} 2$ emissions from sectors such as transport; other sectors, excluding residential buildings and commercial and public services; electricity and heat production; and residential buildings and commercial and public services. In the longrun models, growth $\left(\alpha_{1}\right)$ and the square of growth $\left(\alpha_{2}\right)$ do not appear to have a significant effect on $\mathrm{CO} 2$ emissions in any of the modesl. The long-run findings suggest that $\mathrm{CO} 2$ emissions from transport; residential buildings and commercial and public services; and residential buildings and commercial and public services are essentially related to Islamic finance growth in Indonesia. On the other hand, $\mathrm{CO} 2$ emissions from all sources are inconsequential to economic growth in the country. There is no proof of the applicability of the EKC hypothesis in all models provided short-run and long-run computed models. The findings also indicate that Islamic financial development has a positive impact on $\mathrm{CO} 2$ emissions from the transport sector.

\subsection{Recommendations}

It is inferred that carbon emissions increase with the increase in Islamic financial development and energy consumption. Effective action should be taken by the government of Indonesia to create synergy between energy efficiency and Islamic monetary development; in addition, finance-related organisations must structure the severe approaches to use Islamic residental credit in low carbon emission ventures.

In other sectors, such as residential buildings and commercial and public services, Islamic financial development has a negative impact on $\mathrm{CO} 2$ emissions. This implies that in Indonesia, increasing Islamic financial development, decreasing carbon emissions from the other sectors, residential buildings and commercial and public services sector . The findings of the study do not support the legitimacy of EKC in the case of Indonesia. Therefore, any policy controls related to $\mathrm{CO} 2$ emissions should be appropriately developed and be effective with regard to energy consumption. 
The Islamic finance sector should play its role by protecting the environment through empowering ecologically-friendly and energy-efficient projects. A solid and effective finance sector would help to encourage investment procedures by granting business loans on the condition of controlling carbon dioxide emissions. In this way, the government could expand the issuance of green sukuk aimed at funding climate change action in such a manner that the financing is compliant with Islamic law. The proceeds could be allocated to climate or environmentrelated projects which contribute to the mitigation of or adaptation to climate change, as well as the preservation of biodiversity. This policy could be addressed as the government's ultimate commitment to combatting climate change and to achieve its global emissions reduction goals, aside from being a source of financing the state budget and an effective means for the development of Islamic domestic financial markets.

In this study, there were limited time series data on Islamic banks, hence these were not directly used for the analysis. The finding show that there was no significant effect between the focus variables are alarming, specific, because the Islamic finance industry has not been playing a major role in the Indonesian monetary system for the last 20 years, since the foundation of Bank Muamalat Indonesia in 1999. This is because Islamic finance planned to accomplish two goals: improvement of economic and social conditions. Hence, there are still many parts of this study which could be further investigated in more advanced studies with a broader dataset, including the ongoing years information and progressively variative of monetary improvement proxies . Moreover, to extend understanding of the ecological linkages, and the association of the impacts between Islamic financial development and the other independent variables, use of dynamic econometric models is strongly urged.

\section{REFERENCES}

Abbasi, F., \& Riaz, K. (2016). CO2 Emissions and Financial Development in An Emerging Economy: An Augmented VAR Approach. Energy Policy, 90, 102114. https://doi.org/10.1016/j.enpol.2015.12.017.

Al-mulali, U., \& Saboori, B. (2015). Investigating the Environmental Kuznets Curve Hypothesis in Vietnam. Energy Policy, 76. https://doi.org/10.1016/j. enpol.2014.11.019

Bakar, O. (2007). Environmental Wisdom for Planet Earth: The Islamic Heritage. Malaysia: University Malaya.

Bekhet, H., Matar, A., \& Yasmin, T. (2017). CO2 Emissions, Energy Consumption, Economic Growth, and Financial Development In GCC countries: Dynamic Simultaneous Equation Models. Renewable and Sustainable Energy Reviews, 70, 117-132. https://doi.org/10.1016/j.rser.2016.11.089.

Boutabba, M. A. (2014). The Impact of Financial Development, Income, Energy and Trade on Carbon Emissions: Evidence from The Indian Economy. Economic Modelling, 40, 33-41. https://doi.org/10.1016/j.econmod.2014.03.005.

Clarke, G., Xu, L., \& Zou, H. (2003). Finance and Income Inequality: Test of Alternative Theories. Annals of Economics and Finance, 14. https://doi. org/10.2139/ssrn.364160. 
Danish, Saud, S., Baloch, M. A., \& Lodhi, R. (2018). The Nexus between Energy Consumption and Financial Development: Estimating The Role of Globalization in Next-11 countries. Environmental Science and Pollution Research, 25. https:// doi.org/10.1007/s11356-018-2069-0.

Dickey, D., \& Fuller, W. A. (1979). The Likelihood Ratio Statistics for Autoregressive Time Series with A Unit Root. Econometrica, 49, 1059-1072.

Frankel, J., \& Romer, D. (2017). Does Trade Cause Growth? https://doi. org/10.4324/9781315254166-11.

Furuoka, F. (2015). Financial Development and Energy Consumption: Evidence From A Heterogeneous Panel of Asian Countries. Renewable and Sustainable Energy Reviews, 52, 430-444. https://doi.org/10.1016/j.rser.2015.07.120.

Grossman, G. M., \& Krueger, A. B. (1995). Economic Growth and the Environment. The Quarterly Journal of Economics, 110(2), 353-377. https://doi. org/10.2307/2118443

Halicioglu, F. (2009). An Econometric Study of CO2 Emissions, Energy Consumption, Income and Foreign Trade in Turkey. Energy Policy, 37, 11561164. https://doi.org/10.1016/j.enpol.2008.11.012.

Hidayat, Rachmad; Akhmad, Sabarudin; Mu'alim (2015). Effects of Environmental Factors on Corporate Strategy and Performance of Manufacturing Industries in Indonesia. Journal of Industrial Engineering and Management, 8(3), 763-782. Check names.

Iskandar, A. (2019). Economic Growth and CO2 Emissions in Indonesia : Investigating the Environmental Kuznets Curve Hypothesis Existence. Jurnal BPPK, 12, 42-52.

Islam, F. (2011). Financial Development and Income Inequality in Pakistan: An Application of ARDL Approach. Journal of Economic Development, 36. https:// doi.org/10.35866/caujed.2011.36.1.003.

Islam, F., Ahmed, A., \& Alam, M. M. (2019). Financial Development and Energy Consumption Nexus in Malaysia: A Multivariate Time Series Analysis. https:/doi. org/10.31219/osf.io/tdh8k.

Jalil, A., \& Mahmud, S. (2009). Environment Kuznets Curve for CO2 Emissions: A Cointegration Analysis for China. Energy Policy, 37, 5167-5172. https://doi. org/10.1016/j.enpol.2009.07.044.

Jam, F., Bibi, S., \& Loganathan, N. (2015). Multivariate Granger causality between $\mathrm{CO} 2$ Emissions, Energy Intensity and Economic Growth in Portugal: Evidence from Cointegration and Causality Analysis. Technological and Economic Development, 22. https://doi.org/10.3846/20294913.2014.989932.

Johansen, S., \& Juselius, K. (1990). Maximum Likelihood Estimation and Inference On Cointegration - with Applications to the Demand for Money. Oxford Bulletin of Economics and Statistics, 52, 169-210. https://doi.org/10.1111/j.1468-0084.1990. mp52002003.x.

Kahouli, B. (2017). The Short and Long run Causality Relationship among Economic Growth, Energy Consumption and Financial Development: Evidence from South Mediterranean Countries (SMCs). Energy Economics, 68. https://doi. org/10.1016/j.eneco.2017.09.013

Kamali, M. H. (2012). Environmental Care in Islamic Teaching. Islam and Civilisational Renewal, 3, 261-83. 
Khan, M. T. I., Yaseen, M. R., \& Ali, Q. (2017). Dynamic Relationship between Financial Development, Energy Consumption, Trade and Greenhouse Gas: Comparison of Upper Middle Income Countries from Asia, Europe, Africa and America. Journal of Cleaner Production, 161. https://doi.org/10.1016/j. jclepro.2017.05.129.

Khan, S., Ali, D. A., \& Bhattacharya, M. (2016). The Impact of Globalization on CO2 Emissions in China. The Singapore Economic Review, 1740033. https://doi. org/10.1142/S0217590817400331.

Lau, L.-S., Choong, C.-K., \& Kee, Y. (2014). Investigation of the Environmental Kuznets Curve for Carbon Emissions In Malaysia: Do Foreign Direct Investment And Trade Matter? Energy Policy, 68, 490-497. https://doi. org/10.1016/j.enpol.2014.01.002.

Mahmood, N., \& Masih, M. (2019). Dynamics between Islamic Banking Performance and CO2 Emissions: Evidence from the OIC countries. https:// doi.org/10.13140/RG.2.2.26131.02083.

Mallick, H., Mahalik, M., \& Sadorsky, P. (2016). The Role of Globalization on the recent Evolution of Energy Demand in India: Implications for Sustainable Development. Energy Economics, 55, 52-68. https://doi.org/10.1016/j. eneco.2016.01.013.

Nasreen, S., \& Anwar, S. (2016). Financial Stability,Energy Consumption and Environmental Quality: Evidence from South Asian Economies. Renewable and Sustainable Energy Reviews, 67. https://doi.org/10.1016/j.rser.2016.09.021.

Omri, A., Saida, D., Rault, C., \& Chaibi, A. (2015). Financial Development, Environmental Quality, Trade and Economic Growth: What Causes What in MENA countries. Energy Economics.

Osabuohien, E., Efobi, U., \& Gitau, C. (2014). Beyond the Environmental Kuznets Curve in Africa: Evidence from Panel Cointegration. Journal of Environmental Policy E Planning, 16. https://doi.org/10.1080/1523908X.2013.867802.

Pesaran, H. (1997). An Autoregressive Distributed Lag Modelling Approach to Cointegration Analysis. Science, 7825, 371-413.

Pesaran, H., Smith, R., \& Shin, Y. (2001). Bound Testing Approaches to the Analysis of Level Relationship. Journal of Applied Econometrics, 16, 289-326. https://doi. org/10.1002/jae.616.

Phillips, P., \& Perron, P. (1986). Testing for a Unit Root in Time Series Regression. Cowles Foundation, Yale University, Cowles Foundation Discussion Papers, 75. https://doi.org/10.1093/biomet/75.2.335.

Qayyum Khan, A., Saleem, N., \& Fatima, S. (2017). Financial Development, Income Inequality, and CO2 Emissions in Asian countries using STIRPAT model. Environmental Science and Pollution Research, 25. https://doi.org/10.1007/s11356017-0719-2.

Rehman, I. (2014). Multivariate-based Granger Causality between Financial Deepening and Poverty: The Case of Pakistan. Quality \& Quantity, 48. https:/ doi.org/10.1007/s11135-013-9952-z.

Riti, J., Song, D., Shu, Y., \& Kamah, M. (2017). The Contribution of Energy Use and Financial Development By Source in Climate Change Mitigation Process: A Global Empirical Perspective. Journal of Cleaner Production, 148. https://doi. org/10.1016/j.jclepro.2017.02.037. 
Saboori, B., Sulaiman, J., \& Mohd, S. (2012). Economic Growth and CO2 Emissions in Malaysia: A Cointegration Analysis of the Environmental Kuznets Curve. Energy Policy, 51, 184-191. https://doi.org/10.1016/j.enpol.2012.08.065.

Sadorsky, P. (2011). Financial Development and Energy Consumption in Central and Eastern European Frontier Economies. Energy Policy, 39, 999-1006. https:/ doi.org/10.1016/j.enpol.2010.11.034.

Salahuddin, M., Alam, K., \&Sohag, K. (2017). The Effects of Electricity Consumption, Economic Growth, Financial Development and Foreign Direct Investment on CO2 Emissions in Kuwait. Renewable and Sustainable Energy Reviews. https:// doi.org/10.1016/j.rser.2017.06.009.

Shafik, N., \& Bandyopadhyay, S. (1992). Economic Growth and Environmental Quality: Time Series and Cross-Country Evidence.

Stern, D. (2004). The Rise and Fall of the Environmental Kuznets Curve. World Development, 32, 1419-1439. https://doi.org/10.1016/j.worlddev.2004.03.004.

Tamazian, A., Piñeiro, J., \& Vadlamannati, K. (2009). Does Higher Economic and Financial Development Lead to Environmental Degradation: Evidence from BRIC countries. Energy Policy, 37, 246-253. https://doi.org/10.1016/j. enpol.2008.08.025.

Tamazian, A., \& Rao, B. (2010). Do Economic, Financial and Institutional Developments Matter for Environmental Degradation? Evidence from Transitional Economies. Energy Economics, 32, 137-145. https://doi.org/10.1016/j. eneco.2009.04.004.

Tiwari, A., \& Nasir, M. (2013). The Effects of Financial Development, Economic Growth, Coal Consumption and Trade Openness on Environment Performance in South Africa. Energy Policy, 61. https://doi.org/10.1016/j.enpol.2013.07.006.

Uddin, G., Arouri, M., \& Teulon, F. (2014). Financial Development and Poverty Reduction Nexus: A Cointegration and Causality Analysis in Bangladesh. Economic Modelling, 36, 405-412. https://doi.org/10.1016/j.econmod.2013.09.049. 